\title{
STABILITY OF THE ANTHOCYANINS FROM ACALIPHA HISPIDA AND COPIGMENTATION EFFECT
}

\author{
M. A. BAiloni, P. A. Bobbio and F. O. BobBio \\ Deparmento de Ciência de Alimentos, FEA-UNICAMP - C.P 6121. \\ CEP: 13081-970 - Campinas - SP. Brasil
}

(Received: 27 July 1998; accepted: 11 November 1998)

\begin{abstract}
The stability and stabilization of the anthocyanins to light and air in the crude and partially purified extracts of the leaves of Acalipha hispida were studied at pH 3.0. Addition of non anthocyanic flavonoid fractions from A. hispida to the partially purified extracts did not significantly improve the time of half life of the extracts, whereas addition of tannic acid resulted in an increase of $t_{1 / 2}$ of $60-67 \%$.
\end{abstract}

Keywords: anthocyanins, copigmentation, A. hispida, stability

Consumer's concern (MARKAKIS, 1982) about the use of artifical colours in food and pharmaceutical products has been an important factor in promoting the search for natural non toxic substitutes of some of the artifical colours, mainly red ones.

Anthocyanins are among the natural colours with red to bluish shades that are non toxic, water soluble and could eventually become the most important substitutes for the artificial red colours. Two main problems make this substitution difficult presently: the lack of reliable and cheap sources and the poor stability of anthocyanins to light and high $\mathrm{pH}$. The search for reliable sources of stable anthocyanins has been the subject of many publications i.e.: MOK and HETTIARHCACHY (1991), SHI and co-workers (1992), DOUGALL and co-workers (1997), DuHARD and co-workers (1997). A potential source of anthocyanins for use in food and pharmaceutical products are the leaves of Acalipha hispida for which long term toxicity studies are yet to be made.

According to INAMI and co-workers (1996), acylation improves both heat and light stability, whereas glycosidation only stabilized anthocyanins in the presence of light. The use of tannic acid to stabilize the colour of orange juice from Italian red oranges was proposed in a paper by MACCARONE and co-workers (1987).

In a previous paper (BAILONI et al., 1998) the preparation of a methanolic extract from the leaves of $A$. hispida as well as its concentration and partial purification by reverse-osmosis were reported. The main anthocyanin in the extract was cyanidin-3arabinosyl-glucoside. 
The present paper reports on the stability of the extract and of purified fractions from it as well as on the stabilizing effect of copigmentation.

\section{Materials and methods}

\subsection{Stability of the extract $E_{1}$ to light at $\mathrm{pH} 3.0$ under $\mathrm{N}_{2}$ or air}

Five hundred mg of the crude extract, free of methanol, prepared as described in a previous paper (BAILONI et al., 1998), was dissolved in sufficient amount of citratephosphate buffer at $\mathrm{pH} 3.0$. The $\mathrm{pH}$ of the solution was adjusted to 3.0 by the addition of a few drops of $0.1 \mathrm{~N} \mathrm{HCl}$ and the volume of the solution made up to $100.00 \mathrm{ml}$ with the buffer solution. The slightly turbid solution was filtered and the clear liquid distributed into $10 \mathrm{ml}$ screw-cap tubes. The head space was thoroughly flushed with $\mathrm{N}_{2}$ when needed. The screw-cap tubes were divided in 2 lots. One was kept in the dark at $21 \pm 1.0^{\circ} \mathrm{C}$, while the other was irradiated at the same temperature between two $40 \mathrm{~W}$ lamps, day-light type, with nominal intensity of $2500 \mathrm{~lm}$. Absorptions at $530 \mathrm{~nm}$ were measured from time to time until the loss of absorption reached aproximately $50 \%$.

\subsection{Fractionation of extract $E_{1}$}

Extract $\mathrm{E}_{1}$ was chromatographed on Whatman No. 3 and the chromatogram was developed with $1 \% \mathrm{HCl}$ (FrANCIS, 1982).

A strong red zone, $\mathrm{E}_{2}$, near the top was eluted and dried at $36{ }^{\circ} \mathrm{C}$ under vacuum.

A strip of paper from the chromatogram, when exposed to ammonia vapor turned yellow indicating the presence of a large zone of non anthocyanic flavonoids (NAF) preceding the $\mathrm{E}_{2}$ zone. The NAF fraction was eluted and evaporated under vacuum at $36{ }^{\circ} \mathrm{C}$ to a pale yellow syrup which turned brown on exposure to air and light. Both $\mathrm{E}_{2}$ and NAF were stored under $\mathrm{N}_{2}$ at $-18{ }^{\circ} \mathrm{C}$.

Part of fraction $\mathrm{E}_{2}$ was rechromatographed and the chromatogram was developed with BAW (n-BuOH-HAc- $\mathrm{H}_{2} \mathrm{O}$ 6:1:2) (FrANCIS, 1982). A strong red zone, $\mathrm{E}_{3}$, near the middle part of paper was eluted, dried at $36{ }^{\circ} \mathrm{C}$ and stored at $-18{ }^{\circ} \mathrm{C}$ under $\mathrm{N}_{2}$.

Part of the $\mathrm{E}_{3}$ fraction was rechromatographed using $\mathrm{Bu}-\mathrm{HCl}(\mathrm{n}-\mathrm{BuOH}-2 \mathrm{NHCl}$ 1:1 upper phase) as a developer (FrANCIS, 1982). A narrow red zone $\mathrm{E}_{4}$, in the lower portion of the chromatogram was eluted and dried at $36{ }^{\circ} \mathrm{C}$ under vacuum. Fraction $\mathrm{E}_{4}$ was stored under $\mathrm{N}_{2}$ at $-18{ }^{\circ} \mathrm{C}$.

\subsection{Stability of the purified fractions $\left(E_{2}, E_{3}, E_{4}\right)$ to light and air}

Solutions of each fraction were prepared as in 1.1 and their stability to light and air was estimated as described for fraction $\mathrm{E}_{1}$. 


\subsection{Effect of copigmentation on the stability of the anthocyanic fractions}

Solutions of each fraction $\left(E_{1-4}\right)$ were prepared as described in 1.1. To each fraction sufficient tannic acid was added in order to attain a 3:1 proportion of tannic acid:anthocyanin (w:w) (BOBBIO et al., 1990; 1992).

Approximately the same weight of the fractions $\mathrm{E}_{2}$ and NAF were used to estimate the copigmentation effects of NAF on the anthocyanins.

\section{Results and discussion}

Results presented in Table 1, $t_{1 / 2}$, were obtained from data of Figs 1-9 which represent the average of the absorbance readings from 2 samples. All values of $t_{1 / 2}$ were calculated from absorbance readings up to a maximum of $50 \%$ loss of the initial absorbance.

It has been reported as early as 1931 by ROBINSON and ROBINSON, that NAF can act as a stabilizing agent for anthocyanins by copigmentation, and the NAFanthocyanin association has been considered responsible for the stability of the anthocyanins in plants tissues (ASEM et al., 1972).

Purification of $E_{1}$ with separation of colourless flavonoids did not significantly affect the $t_{1 / 2}$ values of fraction $\left(E_{2}\right)$ (Table 1), but a considerable decrease of the $t_{1 / 2}$ occurred when purifying $E_{1}$, which besides removing flavonoids (NAF) also removed other minor anthocyanins as in fractions $\mathrm{E}_{3}-\mathrm{E}_{4}$.

Table 1

Time of half life (h) for $E_{1}$ and purified extracts $E_{2}, E_{3}, E_{4}$ with copigment at pH 3.0, $20^{\circ} \mathrm{C}$

\begin{tabular}{llr}
\hline \multicolumn{2}{c}{ Reaction conditions } & $\mathrm{t}_{1 / 2}(\mathrm{~h})$ \\
\hline $\mathrm{E}_{1}+\mathrm{N}_{2}+\mathrm{D}$ & (Fig. 1) & 2772 \\
$\mathrm{E}_{1}+\mathrm{N}_{2}+\mathrm{L}$ & (Fig. 2) & 721 \\
$\mathrm{E}_{1}+\mathrm{A}+\mathrm{L}$ & $($ Fig. 3) & 445 \\
$\mathrm{E}_{1}+\mathrm{A}+\mathrm{L}+\mathrm{TA}(1: 3)$ & $($ Fig. 4) & 1103 \\
$\mathrm{E}_{2}+\mathrm{A}+\mathrm{L}$ & $($ Fig. 5) & 459 \\
$\mathrm{E}_{2}+\mathrm{A}+\mathrm{L}+\mathrm{TA}(1: 2)$ & $($ Fig. 6) & 1388 \\
$\mathrm{E}_{3}+\mathrm{A}+\mathrm{L}$ & $($ Fig. 7) & 202 \\
$\mathrm{E}_{4}+\mathrm{A}+\mathrm{L}$ & $($ Fig. 8) & 103 \\
$\mathrm{E}_{2}+\mathrm{A}+\mathrm{L}+\mathrm{NAF}$ & $($ Fig. 9) & 476 \\
\hline
\end{tabular}

A: air; D: dark; $E_{1}$ : crude extract; $E_{2}$ : ext. purified by p.c. $1 \% \mathrm{HCl} ; \mathrm{E}_{3}$ : purified ext. by p.c. BAW; $E_{4}$ : purified ext. by p.c. Bu-HCl ; L: light; NAF: non anthocyanins flavonoids; TA: tannic acid 


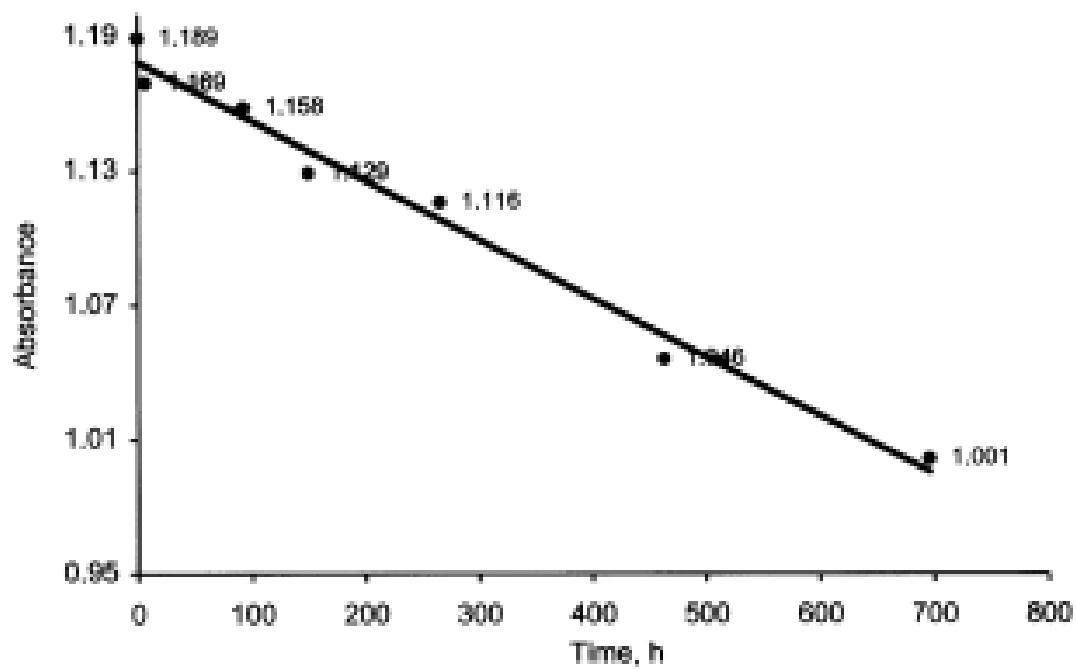

Fig. 1. Loss of absorbance for solutions of $A$. hispida $\mathrm{E}_{1}$ under $\mathrm{N}_{2}$ in the dark. Values are the average of two readings from two samples. $\mathrm{y}=-0.0003 \mathrm{x}+1.1784 ; \mathrm{R}^{2}=0.9827$

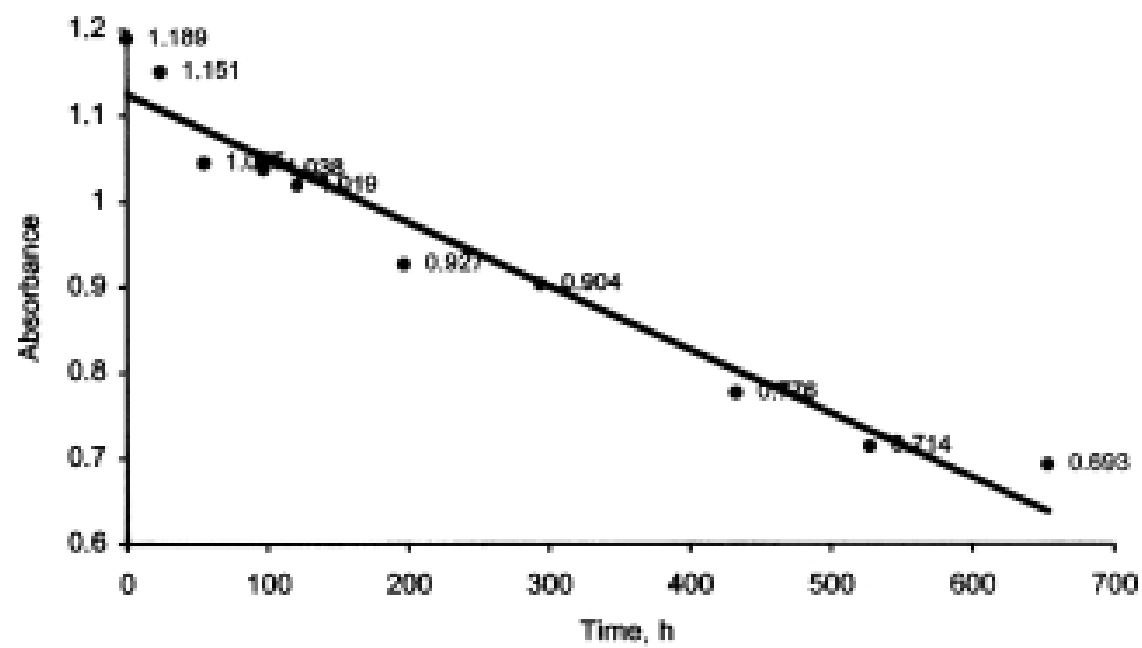

Fig. 2. Loss of absorbance for solutions of $A$. hispida $\mathrm{E}_{1}$ under $\mathrm{N}_{2}$ and light. Values are the average of two readings from four samples. $\mathrm{y}=-0.0007 \mathrm{x}+1.1241 ; \mathrm{R}^{2}=0.9466$ 


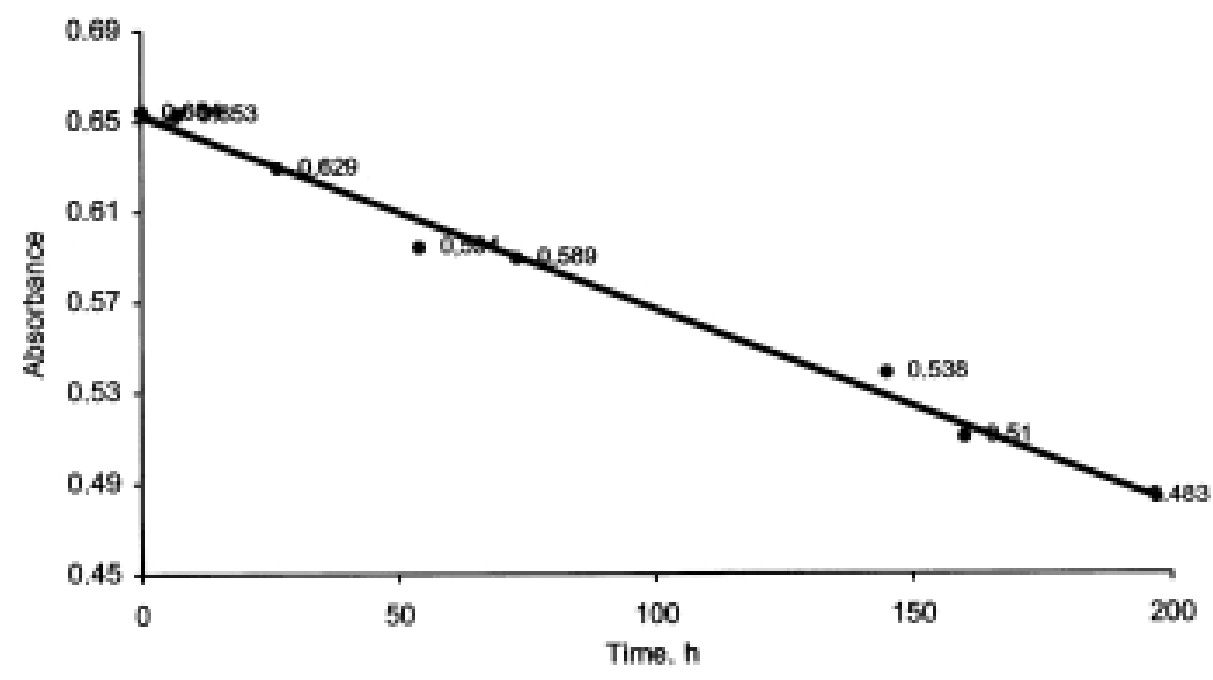

Fig. 3. Loss of absorbance for solutions of A. hispida $\mathrm{E}_{1}$ under air and light. Values are the average of two readings from two samples. $y=-0.0009 x+0.6524 ; R^{2}=0.9892$

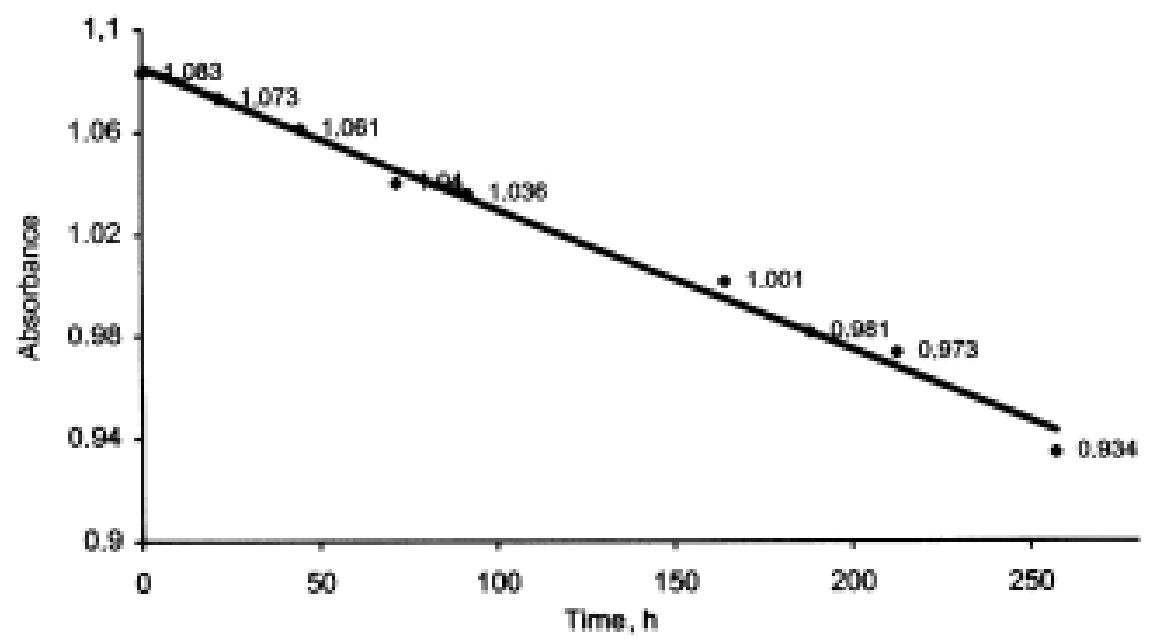

Fig. 4. Loss of absorbance for solutions of $A$. hispida $\mathrm{E}_{1}$ under light and air with addition of tannic acid $(1: 3) . y=-0.0006 x+1.0848 ; R^{2}=0.9908$ 


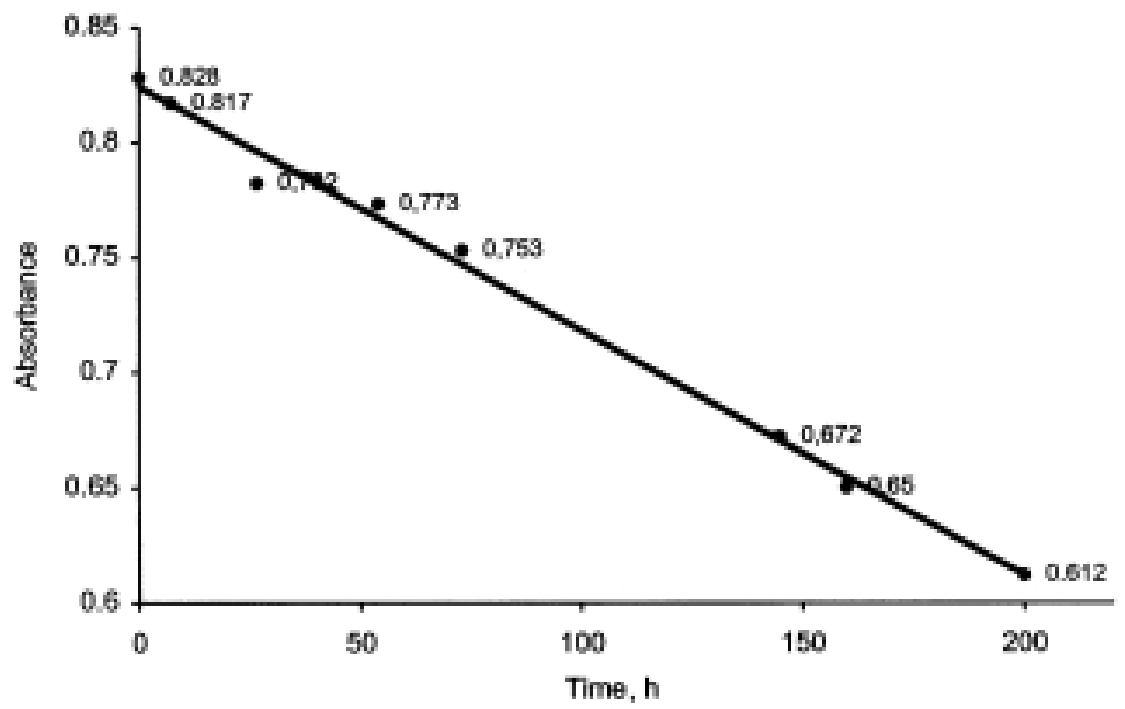

Fig. 5. Loss of absorbance for solutions of A. hispida $\mathrm{E}_{2}$ under air and light. Values are the average of two readings from two samples. $\mathrm{y}=-0.0011 \mathrm{x}+0.8242 ; \mathrm{R}^{2}=0.9932$

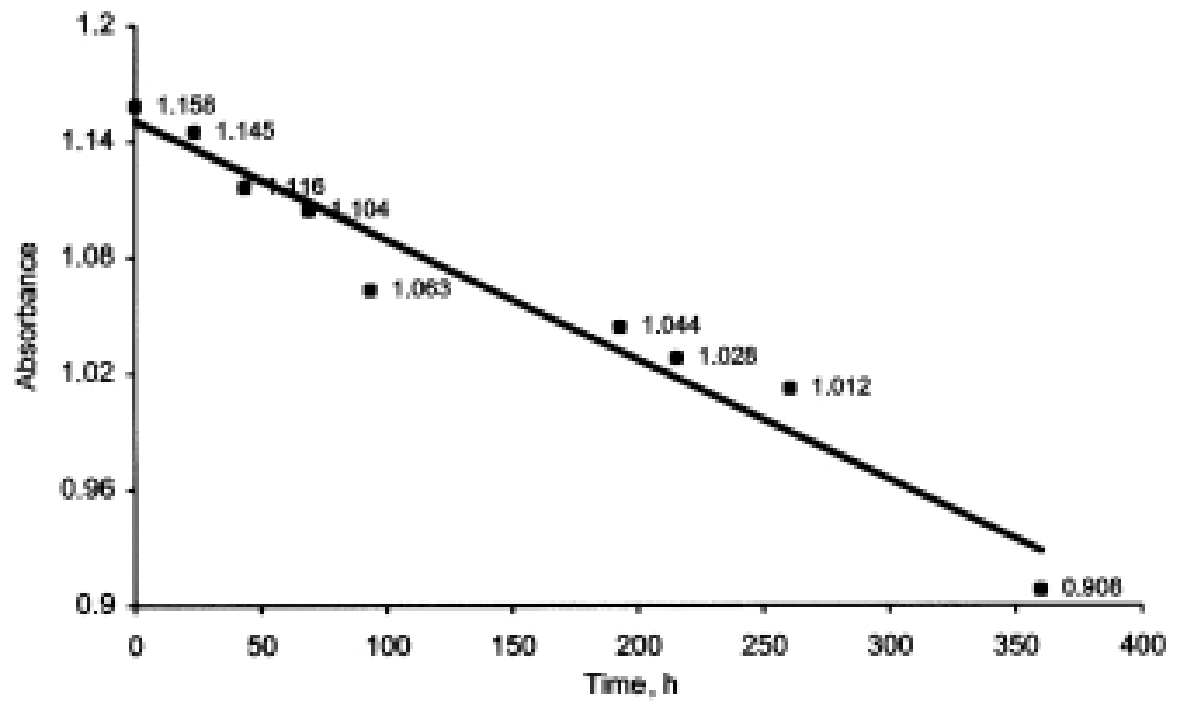

Fig. 6. Loss of absorbance for solutions of $A$. hispida $\mathrm{E}_{2}$ under light and air with addition of tannic acid (1:2). $y=-0.0006 x+1.1505 ; R^{2}=0.953$ 


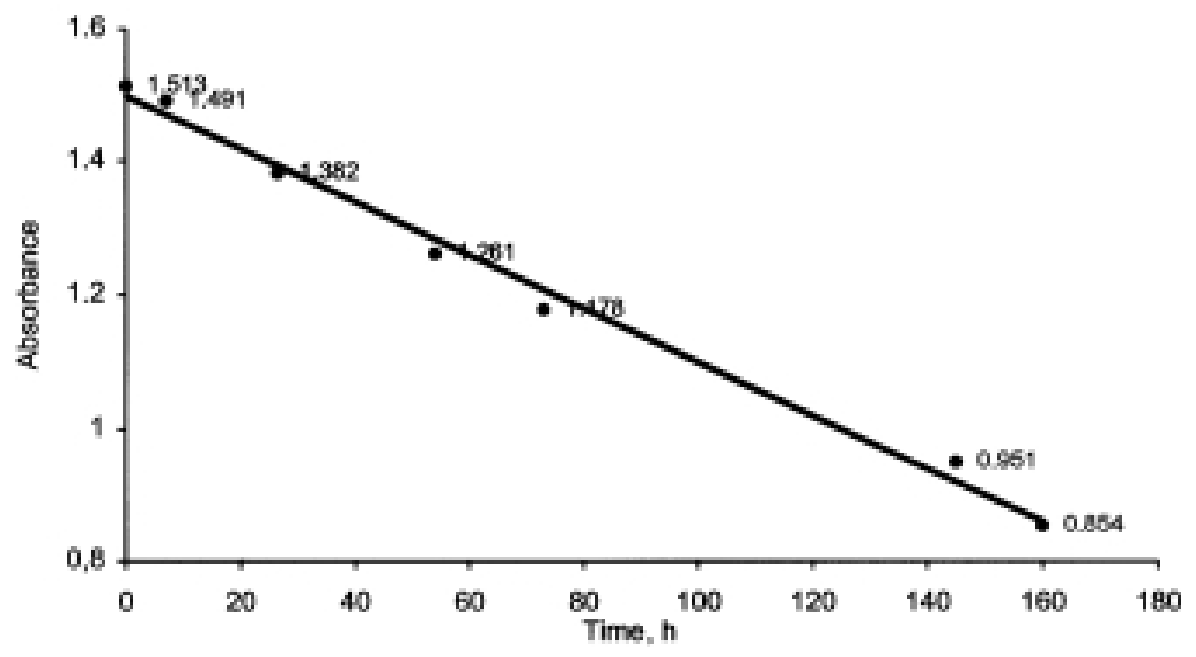

Fig. 7. Loss of absorbance for solutions of A. hispida $\mathrm{E}_{3}$ under air and light. Values are the average of two readings from two samples. $y=-0.004 x+1.4976 ; R^{2}=0.9922$

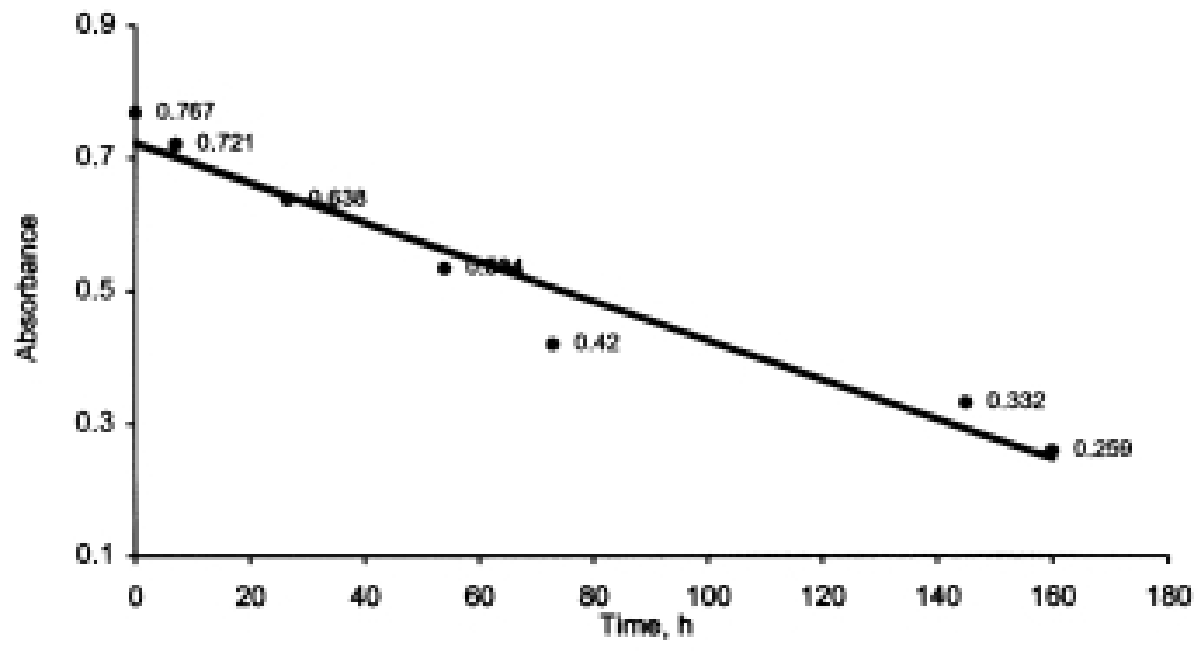

Fig. 8. Loss of absorbance for solutions of A. hispida $\mathrm{E}_{4}$ under air and light. Values are the average of two readings from two samples. $y=-0.003 x+0.7215 ; R^{2}=0.9464$ 


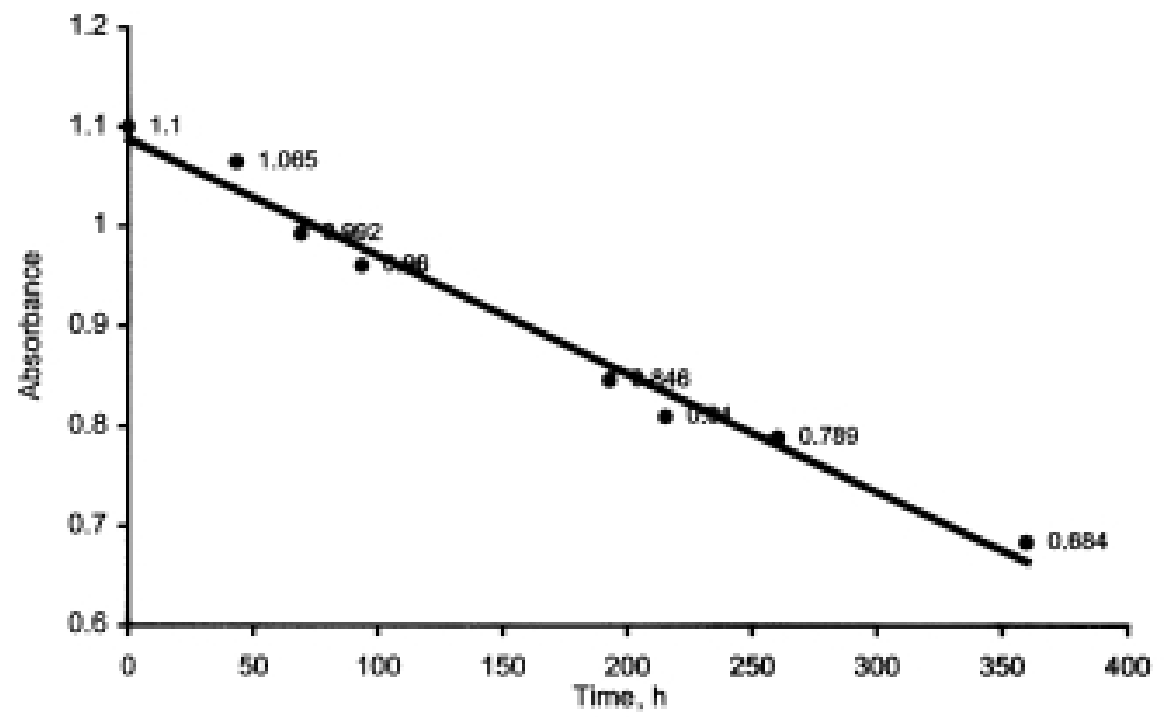

Fig. 9. Loss of absorbance for solutions of $A$. hispida $\mathrm{E}_{2}$ under air and light, with addition of NAF. $\mathrm{y}=-0.0012 \mathrm{x}+1.0872 ; \mathrm{R}^{2}=0.9816$

The addition of the recovered NAF to fraction $\mathrm{E}_{2}$ did not significantly increase its stability (Table 1). The rapid darkening of the NAF fraction by air and light could be in part responsible for its lack of protective effects. Addition of ascorbic acid to the NAF fraction effectively prevented its darkening but the possibility of using ascorbic acid was precluded by the reported destructive effect of ascorbic acid on anthocyanins (MARKAKIS, 1982).

Intermolecular association of anthocyanins has been considered responsible for the stability of the anthocyanins in plants (SCHEFFELDT \& HRAZDINA, 1978). This association as well as copigmentation is easily destroyed by methanol or ethanol (Miniati et al., 1992). The significant decrease of $t_{1 / 2}$ from fraction $E_{1}-E_{4}$ parallels the increase in purity of the main anthocyanin by the progressive elimination of minor anthocyanins, therefore decreasing the possibility of hetero intermolecular associations and stabilization.

Tannic acid, on the other hand, was quite effective in stabilizing the anthocyanin, particularly fraction $\mathrm{E}_{2}$ (Table 1 ). The presence of tannic acid apparently retarded the hydration reaction, which becomes important at $\mathrm{pH} 3.0$ and retarded the formation of the hemiacetalic structure, but did not increase the concentration of the flavilium ion since no significant increase in $\lambda_{\max }$ value was observed. 
By far the most destructive effect on the anthocyanins (Table 1) resulted from the combination of purification, have the light and oxygen. Tannic acid was an effective stabilizing agent, and for fraction $E_{2}$ under light and oxygen, increased the $t_{1 / 2}$ from $459 \mathrm{~h}$ to $1380 \mathrm{~h}$ (Table 1 ).

One of us M. BAILONI gratefully acknowledges a scholarship from FAPESP.

\section{References}

ASEM S., STEWARD, R. N. \& NORRIS, K. H. (1972): Copigmentation of anthocyanins in plant tissues and its effect on color. Phytochemistry, 11, 1139-1141.

BAILONI, M., BOBBIO, P. A. \& BOBBIO, F. O. (1998): Preparation and stability of the anthocyanic extract from leaves of A. hispida. Cienc. Tecnol. Alim. (Campinas, SP), 18 (1), 17-18.

BOBbiO, F. O., BOBBIO, P. A. \& STRINGHETA, P. C. (1992): Stability of copigmented anthocyanins from $P$. mellinis toward light and oxygen at different $\mathrm{pH}$. Proceedings of the XVIth International Conference Groupe Polyphenols. 16 (1), 241-244.

BobBiO, F. O., BOBbiO, P. A., StringheTA, P. C. \& CASTRO, J. O. (1990): Effect of different copigments on the stability of anthocyanins. Proceedings of the XVth International Conference Groupe Polyphenols. 15, 29-31.

DOUGALl, D. K., BAKER, D. C., CAKH, E. \& REDUS, M. (1997): Biosynthesis and stability of monoacylated anthocyanins. Fd Technol., 51 (11), 69-71.

DUHARD, V., GARNIER, J. C. \& MEGARD, D. (1997): Comparison of the stability of selected anthocyanin colorants in drink model systems. Agro Fd Ind. Hitech., 8 (1) 28-34.

FRANCIS, F. J. (1982): Analysis of anthocyanins. -in: MARKAKIS, P. Anthocyanins as food colors. Academic Press, N.Y. ch 7, p. 183-184.

INAMI, O., TAMURA, I., KIKUZAKI, H. \& NAKATA, I. N. (1996): Stability of anthocyanins of Sambucus canadensis and Sambucus nigra. J. agric. Fd Chem., 44 (10), 3090-3096.

MACCARONE, E., MACCARONI, A. \& RAPISARDA, P. (1987): Colour stabilization of orange fruits juice by tannic acid. Intern. J. Fd Sci. Technol., 22, 159-162.

MARKAKIS, P. (1982): Anthocyanins as food additives.-in: Anthocyanins as food colors. Academic Press, N. Y. ch 9, p 245-246.

MINIATI, E., DAMIANI, P. \& MAZ7A, G. (1992): Copigmentation and self association of anthocyanins in food model systems. Italian J. Fd Sci., 4 (2), 109-115.

MOK, C. \& HETTIARCHACHY, N. S. (1991): Heat stability of sunflower-hull anthocyanin pigment. $J$. Fd Sci., $55(2), 553-555$.

ROBINSON, G. M. \& ROBINSON, R. (1931): A survey of anthocyanins I. Biochem. J., 25 (2), 1687-94.

SCHEFFELDT, P. \& HRAZDINA, G. (1978) Copigmentation of anthocyanins under physiological conditions. $J$. Fd Sci., 43, 517-520.

SHI, Z. L., FRANCIS, F. J. \& DAUN, H. (1992): Quantitative comparison of the stability of anthocyanins from Brassica oleracea and Tradescantia pallida in non sugar drink model and protein model systems. $J$. Fd Sci., 57 (3), 768-770. 